\title{
Evaluation of Bronchial Obstruction in Healthy School Children
}

Veera Mohan Rao M *1, Rameswarudu M 2 .

${ }^{* 1}$ Department of Physiology, Kurnool Medical College, Kurnool, Andhra Pradesh, India.

2 Department of Research, SVS M edical College, Mahabubnagar, Telangana, India.

\section{ABSTRACT}

Introduction: In our modern life style even non-smokers and non-exposers to the hazards like mining other pollutants, it is becoming increasingly evident that the air which he is breathing is invariably causing certain amount of Chronic Obstructive Pulmonary Disease (COPD). In this early detection is required to prevent the chronicity.

Objective(s): Evaluation of bronchial obstruction in healthy school children at Kurnool semi urban by using Spirowin (M edicare system, Hyderabad).

Materials and Methods: 23 school going healthy boys were selected randomly, aged between 5 and 16 years. As the pulmonary functions are dependent on the height of the given subject, stratification of the subjects based on their height was made. PEFR, PIF, FVC, and FEV1 were measured using Spirown flow meter and PEFR/PIF ratio was calculated.

Results: The PEFR, PIF, FVC, and FEV1 distributions obtained by Spirown were $308 \pm 45.85 ; 211 \pm 48 ; 138 \pm 34.2$; and $126 \pm 31.2$ respectively. The PEFR, PIF, FVC, and FEV1 distribution in relation to height correlation coefficient obtained for height V/S PEFR, PIF, FVC, and FEV1 were $0.92 ; 0.89 ; 0.89$; and 0.89 respectively.

Conclusion: suggesting that the study group not have any respiratory obstructive disorder. This data representative data for the locality of semi urban Kurnool.

KEY WORDS: PEFR, PIF, FVC, FEV1, and Height.

Address for correspondence: Dr. Veera M ohan Rao M, Department of Physiology, Kurnool M edical College, Kurnool, Andhra Pradesh, India. E-Mail: drveeramohan8@ gmail.com

\begin{tabular}{|c|c|c|}
\hline \multicolumn{3}{|c|}{ Online Access and Article Informtaion } \\
\hline \multirow{2}{*}{$\begin{array}{c}\text { Quick Response code } \\
\text { Dol: } 10.16965 \text { ijims.2017.101 }\end{array}$} & \multicolumn{2}{|c|}{$\begin{array}{c}\text { International Journal of Integrative Medical Sciences } \\
\text { www.imedsciences.com }\end{array}$} \\
\hline & $\begin{array}{l}\text { Received: 15-01-2017 } \\
\text { Reviewed: 16-01-2017 }\end{array}$ & $\begin{array}{l}\text { Accepted: 20-02-2017 } \\
\text { Published: 28-02-2017 }\end{array}$ \\
\hline Source of Funding: Self & \multicolumn{2}{|c|}{ Conflicts of interest: None } \\
\hline
\end{tabular}

\section{INTRODUCTION}

Under civilization, increased automobiles and various types of chemicals used in aerosols, the atmosphere is getting highly polluted. Even nonsmokers and non-exposers to the hazards like mining other pollutants, it is becoming increasingly evident that the air which he is breathing is invariably causing certain amount of Chronic Obstructive Pulmonary Disease (COPD) [1]. In this early detection is required to prevent the chronicity.

Air pollution is also capable of causing lung damage in the school going children. Now it is more relevant to screen the children for any pulmonary disorders prior to the appearance of a symptomatic disease [2]. The more expensive and cumbersome instrument cannot be employed for the detection and evaluation of lung disorders as ubiquitous nature of pollution increases the sample size. This necessitates the application of a simpler device which can be obtained any number of times and number of respiratory parameters can be simultaneously obtained. The Spirown flow meter is one such device which is being employed universally for the recording of an important pulmonary function 
Test namely Peak Expiratory Flow rate (PEFR), this having a bidirectional turbine and A.D. converter can be directly coupled to computer where by virtue of applying proper software. Predictive normal values are essential for meaningful clinical interpretation of these tests. Studies carried out in children had projected the equations for predicting different lung functions using height, age and weight as independent variables in India [2-5] and in other countries [67] Thus the functional standards are to be obtained for a particular locality. Apart from that, the standardization of a particular instrument for subsequent evaluation becomes a more necessity. This prompted us to take up the study of Peak Expiratory Flow rate in school children of our Kurnool locality among the school boys and to evaluate the Spirown instruments available with us.

\section{MATERIALS AND METHODS}

It is an observational study, permitted by the institutional ethical committee. After thorough explanation about this study, subjects were included after obtaining the written informed consent from their school authorities. 23 school going healthy boys were selected randomly, aged between 5 and 16 years. Anthropometric parameters, namely, height and weight of the subjects were measured to the nearest reading with minimal clothes on and without footwear using stadiometer and weighing machine, respectively.

Exclusion Criteria: for the present study we excluded the people with certain conditions such as Smoker's, subjects with $\mathrm{H} / \mathrm{O}$ recurrent respiratory tract infections, $\mathrm{H} / \mathrm{O}$ bronchial asthma, $\mathrm{H} / \mathrm{O}$ congenital respiratory problems, deformities of the spine, recent $\mathrm{H} / \mathrm{O}$ surgeries, and $\mathrm{H} / \mathrm{O}$ continuous exposure to the industrial dust (cotton mills, etc.) are all excluded from the study.

Methodology: As the pulmonary functions are dependent on the height of the given subject, stratification of the subjects based on their height was made. PEFR, PIF, FVC, and FEV1 were measured using Spirown flow meter and PEFR/ PIF ratio was calculated.

Statistical Analysis: Data were analysed by Statistical Package for Social Sciences version
23.0. Data were summarized by mean \pm standard deviation for continuous normal data. The relation between height (in $\mathrm{cm}$ ) and PEFR, PIF, FVC, and FEV1 were carried out with Karl Pearson's correlation coefficient for continuous normal data.

\section{RESULTS}

Table 1: Showing the PEFR, PIF, FVC, and FEV1 Distribution in relation to Height (in $\mathrm{CM}$ ).

\begin{tabular}{|c|c|c|c|}
\hline & Mean \pm SD & $\begin{array}{c}\text { Height with } \\
\text { Mean } \pm \text { SD (in cm) }\end{array}$ & $\mathbf{r}$ \\
\hline PEFR & $308 \pm 45.85$ & $154 \pm 7.85$ & 0.92 \\
\hline PIF & $211 \pm 48$ & $154 \pm 7.86$ & 0.89 \\
\hline FVC & $138 \pm 34.2$ & $154 \pm 7.87$ & 0.89 \\
\hline FEV1 & $126 \pm 31.2$ & $154 \pm 7.88$ & 0.89 \\
\hline
\end{tabular}

\section{DISCUSSION}

In this study total 23 school going 5-16 years Childers were included randomly. The values of respiratory parameters like PEFR, PIF, FVC, and FEV1 were obtained by using Spirown (medicare system, Hyderabad). Their mean Height is $154 \pm 7.85 \mathrm{cms}$.

The PEFR, PIF, FVC, and FEV1 distributions obtained by Spirown were $308 \pm 45.85 ; 211 \pm 48$; $138 \pm 34.2$; and $126 \pm 31.2$ respectively. The PEFR, PIF, FVC, and EEV1 distribution in relation to height correlation coefficient obtained for height V/S PEFR, PIF, FVC, and FEV1 were 0.92; 0.89; 0.89 ; and 0.89 respectively. These recordings were suggesting a very good correlation. Since FVC and FEV1 recorded in a single manoeuvre go hand in hand, they are giving consistent value of correlation coefficient.

The FVC and FEV1 values given by the R.V. Chowgule et $a^{3}{ }^{3}$ for boys between age ranges 6 15 years from the Bombay are $156 \pm 1.8$ and $138 \pm 1.8 \mathrm{~L} / \mathrm{m}$ respectively. The values in the present study were lower than the above study because of metropolitan Bombay and Semi urban locality of Kurnool, the difference can be explained in terms of change in social status.

M alik S.K. et al [2] the PEFR values in that study were obtained by wrights Peak Flow M eter. The correlation coefficient for PEFR v/s Height in their study is 0.8825 which lower than the present study.

From the same study group, the mean PEFR being 
$308 \pm 45 \mathrm{~L} / \mathrm{m}$ and the mean PIF $211 \pm 48 \mathrm{~L} / \mathrm{m}$, the ratio between PEFR and PIF is calculated. The value obtained is 1.46 as against the value obtained by Rajendra Prasad et al [8] being 1.5. The PEFR signifying expiratory manoeuvre and PIF signifying inspiratory manoeuvre, the ratio of 1.5 , signifies that there is no bronchial obstruction. In most of the COPDs, more commonly in bronchial asthma where the obstruction is more for expiration, the PEFR values decrease very much as compared to PIF values. Hence the ratio in present study being 1.46 clarifies that the subjects in the present studies are not suffering from bronchial obstruction. Since the PEFR/PIF ratio is a very useful indicator for evaluating the bronchial obstruction.

Similar to our study Doctor $\mathrm{TH}$ et al. [9] also found Variables such as FVC, FEV and PEFR show good positive correlation with height, age and body surface area in both sexes. There is a need to have regional values for the prediction of normal spirometric parameters in a country like India with considerable diversity.

\section{CONCLUSION}

In this study total 23 school going 5-16 years Childers were included randomly. The values of respiratory parameters like PEFR, PIF, FVC, and FEV1 were obtained by using Spirown (medicare system, Hyderabad). Their mean Height is $154 \pm 7.85 \mathrm{cms}$. The PEFR, PIF, FVC, and FEV1 distributions obtained by Spirown were $308 \pm 45.85$; $211 \pm 48 ; 138 \pm 34.2$; and $126 \pm 31.2$ respectively. The PEFR, PIF, FVC, and FEV1 distribution in relation to height correlation coefficient obtained for height V/s PEFR, PIF, FVC, and FEV1 were 0.92; $0.89 ; 0.89$; and 0.89 respectively. These recordings were suggesting a very good correlation. The correlation coefficient is suggestive of positive correlation for the PEFR, PIF, FVC, and FEV1 with Height when it is done with Spirowin. The ratio of PEFR to PIF being 1.46 suggesting, that the study group not have any respiratory obstructive disorders. Data collected in the study representing semi urban Kurnool. There is a need to have regional values for the prediction of normal spirowin parameters in a country like India with considerable diversity.

\section{ABBREVIATIONS}

PEFR - Peak Expiratory Flow Rate

PIF - Peak Inspiratory Flow

FVC - Forced Vital Capacity

FEV1 - Forced Expiratory Volume in 1 Second

\section{ACKNOWLEGEM ENT}

We thank all the school children who participated enthusiastically in the study.

\section{REFERENCES}

[1]. Frank J. Kelly, Julia C. Fussell. Air pollution and public health: emerging hazards and improved understanding of risk. Environ Geochem Health. 2015; 37(4): 631-649.

[2]. Mallik SK, Jindal SK. Pulmonary function tests in healthy children. Indian Pediatr 1985;22:677-81.

[3]. Chowgule RV, Shetye VM , Parmar JR. Lung function tests in normal Indian children. Indian Pediatr 1995;32:185-91.

[4]. Sharma PP, Gupta P, Deshpande R, Gupta P. Lung function values in healthy children (10-15 years). Indian J Pediatr 1997;64:85-91.

[5]. Nair RH, Kesavachandran C, Sanil R, Sreekumar R, Shashidhar $\mathrm{S}$. Prediction equation for lung functions in south Indian children. Indian J Physiol Pharmacol 1997;41:390-6.

[6]. Connett GJ, Quak SH, Wong M L, Teo J, Lee BW. Lung function reference values in Singaporean children aged 6-18 years. Thorax 1994;49:901-5.

[7]. Shamssain M H. Forced expiratory indices in normal black southern African children aged 6-19 years. Thorax 1991;46:175-9.

[8]. R. Prasad, R.Gupta, S.K. Verma. A Study on Perception of Patients about Bronchial Asthma. Indian J Allergy Asthma Immunol. 2003;17(2):85-7.

[9]. Doctor TH, Trivedi SS, Chudasama RK. Pulmonary function test in healthy school children of 8 to 14 years age in south Gujarat region, India. Lung India. 2010;27(3):145-8.

How to cite this article: Veera Mohan Rao M, Rameswarudu M. Evaluation of Bronchial Obstruction in Healthy School Children. Int J Intg Med Sci 2017;4(1):462-464. DOI: 10.16965/ ijims.2017.101 